Article

\title{
The What, Who, and How of Ecological Action Space
}

\section{Karin Skill}

Department of Management and Engineering, Political Science, Linköping University, S-581 83 Linköping, Sweden; E-Mail: karin.skill@yahoo.com.ar; Tel.: +46-13-281806; Fax: $+46-13-281101$

Received: 12 October 2011; in revised form: 28 November 2011 / Accepted: 13 December 2011 / Published: 28 December 2011

\begin{abstract}
This text presents an analytical concept which is aimed at analysis of the construction of environmental responsibility - ecological action space. The concept makes it possible to analyze what environmental activities householders perform, who takes on the environmental responsibility, and how they motivate and justify everyday practices in relation to other actors. The concept builds on structuration theory, and is useful in studies of sustainable development in everyday life, and in investigations about how actors perceive their role in creating and solving environmental problems, and what actions they take in light of this. The concept should be used for empirical rather than normative studies. Relevant questions for a study about ecological action space are: What activities are considered environmentally friendly? How do the actors conceive of their opportunities to act in environmentally friendly ways and what constraints do they express? These questions are relevant not just for outspoken activists. When promoting increased participation, it is valuable to discuss when, where and how people are expected to get involved.
\end{abstract}

Keywords: ecological action space; structuration theory; sustainable development; householder; environmental activities; ecological citizenship; individualization; environmental responsibility

\section{Introduction}

We have to make our lives in a more active way than was true of previous generations, and we need more actively to accept responsibilities for the consequences of what we do and the lifestyle habits we adopt [1]. 
This has largely come to be true for activities that influence the environment, but this social expectation does not necessarily imply that individuals change their practices to accommodate to it. The present text is about the encounter between individual citizens, authorities and the political goal of sustainable development. There was a historic shift from the 1960s and 1970s when the environmental problems were portrayed as industrial problems, and now when they are mainly framed as (individual) consumer problems. It follows that if humans change their practices, these environmental problems can be alleviated. Policies for sustainable development thus includes the private sphere - the household - in a way that seems to politicize everyday doings in its demand to change everyday practices. Through policy advice from authorities individual citizens are expected to choose to perform "sustainable" or green activities, like recycling, saving energy and purchasing organic products, while authorities and companies are expected to supply systems for these services. These activities become a form of political participation. Wide public participation has had a central role in the documents of sustainable development, especially Agenda 21 [2]. When promoting increased participation it is valuable to discuss when, where and how people are expected get involved. Previous studies and models in which only certain activities were considered political acts, such as voting, demonstrating, or being a member of a political party, need to be examined [3-5]. With the introduction of sustainable development, environmental concern no longer necessarily means social criticism, since it does not require structural change of the capitalist system; rather, environmental problems are expected to be solved using technological and institutional "fixes" [6], and "without leaving the path of modernization" [7].

This article is multidisciplinary, and draws on several theoretical resources. It emphasizes how the individual householder should be understood in his or her context, and is far from being an autonomous actor with unlimited capacities and opportunities to design and chose his or her ecological action space. The concept ecological action space takes as its point of departure that the actor can be understood only in relation to the systems and structures in which he or she exists. It is the encounter that is interesting. The structures are simultaneously created and recreated through praxis, which Anthony Giddens [8] emphasizes in structuration theory that forms the basis for the concept. Living everyday life without routines would be impossible. Routines limit the alternatives that are considered. To be able to understand how householders can reduce their individual impacts on the environment, it is important to understand what makes up their action space among the alternatives that exist. In many documents for sustainable development, there is a central assumption that if people are made aware of environmental problems by providing information or increasing their knowledge, their practices may change. However, people can be motivated to act in less environmentally detrimental ways out of concern for the health and wellbeing of others in distant places, or with more egotistical concerns and risk perceptions, or, they may not simply care about the environment at all. We need a concept that can analyze both those who consider themselves to care for the environment, as well as those who do not.

The aim of the article is to discuss how to analyze everyday (seemingly private) environmentally motivated household activities, and situate the understanding in a wider political and social context by using the concept ecological action space. It is a multidisciplinary and qualitative concept, which can be used to analyze environmental activities and perceptions about environmental responsibilities in different contexts. It is vital to state that it is not a moral or normative concept, even if environmental care often is turned into a moral issue. In order to develop the concept I will go through some of the 
now extensive literature on ecological activities and sustainable development, and show what it relates to, what it incorporates and what it rejects or questions. The paper builds on fieldwork in Sweden during 2004-2006, where the author performed two separate interviews with 28 households, with different numbers of members (householders) and let them write time-diaries about their everyday activities between the interviews; and performed interviews with municipal representatives from four Swedish municipalities. Through the study it became clear that many householders had incorporated a discourse of individual responsibility, and expressed "bad conscience" when they did not perform environmental activities they knew they possibly could. The householders constantly related their own activities to others, and justified and explained what environmental activities they performed or did not perform, in relation to socio-cultural conventions, and relations, like: "I cannot bicycle to work because I would get there sweaty", "I teach my children to save resources" or "I think that school should teach children about environmental issues", "I believe that we Swedes are environmental leaders in the world", or "we have tried to organize a car pool with neighbors, but they want to drive their own car". These are examples that motivate the use of structuration theory that emphasizes relations between actors and structures.

\subsection{The Political Context for Responsibility}

Many environmental problems cross national borders and call into question the traditional views of citizenship by confronting belonging and community by posing questions like for whom are we responsible — do we need to be responsible for our "ecological footprints" [9] wherever the ecological consequences arise?

The development of this article is mainly based on the historical, cultural and political context of Sweden, which may limit some of the conclusions, at the same time as the concept presented is assumed to be useful for analysing different political and national contexts. In Sweden, the municipalities have been given the responsibility to create the proper conditions to comply with the global and national goals, and households have been mentioned as important actors or micro-institutions in efforts to reach a more sustainable future through participation [10]. It is not only in policies for sustainable development that we find an emphasis on the individual, they are present in academic theories too, as will be shown later in the text. In the 1990s, green political theories took a deliberative turn, with a heavy focus on wide participation in verbal communication to solve what has been framed as shared environmental problems [11,12]. The environmental problems created by individual consumption cannot be governed by the same means as are used to control industrial emissions, namely, permits and control measures. Due to this perception among authorities, citizens, often in their role as consumers, are anticipated to be informed and educated about how they can change their lifestyles and habits to make them more environmentally friendly [13]. However, the same authorities do not considered information to be enough. This is how the Swedish Environmental Protection Agency expresses the matter:

In a democracy, citizens should preferably act in environmentally friendly ways because they want to, not because they are forced to or convinced. Unfortunately, it is not enough to rely on citizens' voluntary compliance in environmental efforts, because that would make progress towards environmental goals too slow. Therefore, society has a variety of policy instruments to 
influence people to change their behavior and lifestyle, and thereby increase the pace of efforts to achieve sustainable development [13].

In this quotation we can see how a Swedish authority expresses themselves - something which the individual actors have to relate to. The interaction between actors and structures is emphasized in structuration theory, and the policy instruments are part of the political structure wherein citizens act. The ideal of voluntarism is central to many green theories, as are expectations of harmonious cooperation for the common good (an improved environment) and reliance on a high level of shared values and commitment. However,

...the fact is, an enormous number of people don't care about the environmental consequences of their actions, and they're not going to be talked into caring anytime soon. We cannot expect them to voluntarily adopt eco-friendly practices [14].

The tension between voluntarism and force emphasizes the question of how to make citizens change their practices with policy instruments, which concerns the circumstances and incentives that facilitate environmentally friendly practices and the constraints that exist. Because many activities are actually politically relevant, the notion of when a person is an "active" or "passive" citizen has been challenged. The issue of what householders do deliberately and/or "thoughtless" comes to the fore, emphasizing the concept of "decisions" when arranging everyday life [5]. In this text I take as a point of departure that no matter what citizens do (or do not do) they/we maintain a relationship with the environment through everyday practices, and thus we need a concept that can incorporate different approaches among householders.

Sustainable development builds on what has been called "voluntary simplicity," i.e., decreased consumption and de-materialization $[15,16]$. What we consume has consequences for others through our ecological footprint, so consumption is political [4,9]. By means of changed consumption patterns through active choice, consumers are expected to contribute to more environmentally sustainable production practices Various studies demonstrate, however, that our resource consumption is continuously increasing $[17,18]$. Being able to purchase whatever one wishes in "consumer culture" is based on the norm of convenience and quality of life, while refraining from consuming is considered a sacrifice.

Here the aim is to understand what it means to be environmentally friendly, what is called construction of environmental responsibility. The question should not be interpreted in a predetermined moralistic sense, confirming that individual citizens ought to have responsibility [4], but rather focus on the construction aspect, and how householders view and reason about their role. The responsibility to solve environmental problems can be divided into dealing with the causes and preventing them from arising, or managing existing problems through adaptation. A person may consider someone else to be responsible for causing environmental problems, but it is her citizen responsibility to help in solving them. On the other hand, it is equally possible to argue that her everyday activities cause environmental problems, but others-like corporations or politicians- are the ones who need to solve them. Suggestions for what to do to solve environmental problems may also differ. 


\subsection{Structuration Theory and Praxis}

This article focuses on practices, and investigates the activities and motivations of householders concerning their relationship with the environment. A central point of departure is that social, material and institutional structures both govern and facilitate individual action, so research should focus on the relationship between structures and agency [19,20]. With structuration theory, the aim is to analyze the opportunities and constraints householders perceive in their everyday activities in relation to sustainable development. Praxis is at the intersection between saying and doing [8], and can be used to examine how people justify their activities.

Human societies, or social systems, would plainly not exist without human agency. But it is not the case that actors create social systems: they reproduce or transform them. Remaking what is already made in the continuity of praxis [8].

The focus on agency relates to being able to act otherwise or to intervene in the world. The structural properties of social systems create certain opportunities for action at the same time as they restrict others: they are both enabling and constraining [8]. The concept of constraint is used to discuss the factors that limit the available options for action; they are not unlimited [8]. The structures are both the preconditions for action and the outcome. This is where structuration theory can face criticism, since it posits structure as both the cause and effect of phenomena [21].

The constraint concept is taken to mean that some resources are, or are perceived to be, limited or limiting. Access to resources, such as tools, knowledge, or technology, affects the activities humans believe they can do. Culturally created expectations and obligations may be taken for granted that they are perceived as obstructions to changing practices (e.g., to incorporate new environmentally friendly activities, or changing existing ones). There may be a discrepancy between the expectations of the surrounding society and the perceived ability of the individual.

In everyday life, humans participate in a continuous flow of action, where far from all intentions result in the intended outcomes. Intentional activities may have unintended consequences, as well as the other way around: Few people intentionally aim to destroy the environment, but it can be the unintentional consequence of everyday life in which people go about their routines. Human agency should thus not stop at intentionality.

Several academics have shown an interest in the practice of everyday life [22], and suggested ways to register and articulate ordinary experience methodologically. The ability to make the everyday life "strange" deals with the relationship between routines and interruptions "that might allow for the everyday to emerge" [23]. However, it is not possible to relate to everything that is going on around us: we cannot perceive it all. In her book, Comfort, Cleanliness and Convenience [18] Elizabeth Shove directs our focus towards inconspicuous consumption and materiality, and "the intangible, immaterial and invisible services they make possible" [18]. We are thus not only consuming natural resources through everyday life. In certain contexts, like planning and architecture, some attempts have been made to "build" environmental care into dwellings, but with rather mixed results since the inhabitants are using their "agency" when they move in and start to make home [24]. In this sense, the environment or surrounding does not determine human agency. 


\subsection{Previous studies of Households}

Individual actions contribute at an aggregate level. But it is difficult to investigate how individual actions affect others directly and actually to demand individual accountability from a juridical perspective; it is easy to free-ride. From a perspective offered by feminists among others who focus on difference, it is possible to argue that richer segments of the population have the option of buying their freedom, by using their economic assets to move to safer or less risk-prone places or to purchase less hazardous products [25]. When feminists incorporated women's (everyday) lives and domestic routines into the picture, and argued that the personal is political, they provoked a transformation of politics itself [23]. The attention given here to gender as a form of difference thus has a form of historical legacy in everyday studies, and is not intended to neglect other forms of differences like ethnic, age and socio-economic such, but adhere to recent developments that highlights that differences may intersect. This shifts the focus towards a differentiated humanity.

Previous studies of environmental activities in households have examined individuals' environmental attitudes and norms and their relationship to behavior [26]; performed life cycle analysis of grocery consumption and household waste [15]; studied unpaid household work and division of labor [27]; household use and access to technology and socio-technical systems [18,28]; time use [29]; and how households use and "recontextualise" knowledge into practice in everyday life [30]. While many previous studies have investigated green activists [25,31] and those living in communal ecological arrangements [27], there is still a need to investigate people who fall outside these categories. Many studies have focused on specific activities, and attitudes that concern sustainable development, such as choice of mode of transportation, waste management, and purchases of environmentally labeled groceries. These studies often have a narrow approach to isolated phenomena [32]. The concept ecological action space attempts to incorporate everyday life, and the yet underresearched area of how environmentally motivated activities relate to all other household activities. Here household activities are taken to be all activities that are not paid labor. Using this definition draws a multitude of activities into the purview.

\section{Ecological Action Space in Householders Everyday Life}

The relationship between actors and structures concerns whether individuals are governed by the structures, or whether individuals can contribute to and actively change their conditions of life. The routines, actions, and possible actions that individuals have at their disposal are at the center. To illustrate the argument we can use a recycling station. The existence of the recycling station is part of the physical structure, it is a system which has an intention from certain actors, it most probably relate to a wider system including roads, machines, natural resources and technologies, and it can be used (or not) in many different ways by individual actors. The sheer existence of it does not imply that it is used, or that it is used in the intended way.

As mentioned in the introduction, part of the aim with the concept ecological action space was to deal with the extensive literature on single ecological and environmental activities. It is worth commenting on the use of the terms 'ecological' and 'environmental' here. A common distinction between the two has been to view ecological movements as wanting to reform the modern industrial 
society, and environmental movements as wanting simply to mitigate the negative impacts of industrial society. In this sense it could have been equally possible to use environmental action space, as ecological. The decision to use ecological action space was taken in relation to "ecological citizenship", and "ecological modernization", which both influenced the development of the concept.

Rational choice theory has been influential in studies of environmental activities. Individuals are expected to make systematic choices from among similar alternatives, and to consider the consequences of the different alternatives. This is in line with the expectations of ecological citizenship theory [4], which I will deal with in a while. Others have questioned the possibility of actually gaining an overview of environmental influences and consequences, for example, concerning production chains and consumption, since society is so complex [33]. Taking structuration theory as a point of departure, the ecological action space is considered the context in which an individual acts and exerts an impact on the environment and other humans, and their own reflection on the praxis, the actual action space being both created and recreated by the individual in interaction with surrounding structures and systems. It has a time dimension, in that what is done here and now is based on previous experiences and actions, and simultaneously influences future opportunities for action.

Central documents on sustainable development, such as Agenda 21 [2] and the Aarhus Convention [34], stress the need for participation by all citizens in the change towards a more sustainable future society. This emphasis makes it useful to use political theories in addition to structuration theory. Different theories of political participation put different degrees of emphasis on rights/entitlements and responsibilities/obligations for citizens and states, and on the conditions under which they can be materialized. A challenge to citizenship theory concerns how the citizens participate politically: at what stage, and through what activities are they considered to exert an impact. Thus, citizenship should not be limited to voting in popular elections, since many of our everyday activities have political implications [4,32].

How people join in public discourse is open to interpretation, and there are various strategies "tied to broader patterns of political culture and perceptions of individual and collective responsibilities, and of one's own role in politics" $[3,35]$. It is assumed that people will readily accept policies that they have participated in creating [36]. However, people are just as likely to participate in deliberative processes and agree on less green ideas, or act in contradiction to ecological aims (if they participate at all), and there is no empirical evidence that deliberative democracy is more ecologically rational [37]. While there are indeed non-verbal forms of communication in an environmental-political context (such as consumer power), analysts usually emphasize verbal forms, such as discussion and deliberation. In short, political participation is about voicing an opinion or standpoint using available means and strategies.

\subsection{Householders as Actors in Structures}

Through the concept ecological action space the attempt is to come to terms with the relationship and encounter between actors and structures, and focus on what happens in the interaction. It has already been mentioned that the plentiful literature on environmental and sustainability discourse has come to focus on individuals and their choices and agency. Even if the idea of individual responsibility exists in society, many times householders also know how to relieve themselves of the responsibility 
through different "excuses" [38,39], they relate to the (often moralistic) environmental discourse. Specific segments of activities can excuse other-less environmentally friendly-activities that are considered as interchangeable. An example could be the statement: "I drive my car far too much, but I do recycle", or the idea that purchasing eco labeled milk is "doing enough". In other political contexts, citizens would not necessarily have "bad conscience" for something that the Swedes interviewed in this study expressed.

Individualization has influenced many areas of contemporary society [19], not just the sustainability discourse. However, there are different aspects of the phenomena; some researchers focus on the increased autonomy of individuals and their increased control of their life histories and independence from large collectives, including self-realization [40], while others emphasize increased individual responsibility and accountability [1,29]. The meaning of individualization is central here due to the focus in policies, theories and society on individual responsibility for the environment $[1,4]$. The view of individualization as autonomy conceals all the social relationships, systems and structures on which individuals are dependent through unpaid life-sustaining work in the private sphere, such as domestic production, reproduction, caring, and family relationships [4,29]. Placing the responsibility for change on individuals diverts attention from structural aspects, such as governments, technological systems, society, and institutions [29,33,41].

Both Beck and Giddens argue that individuals have no choice but to choose how to act in our current society $[42,43]$. In this light, individualization also means that individuals have an obligation to justify their decisions, as does a person who works for a company that is causing environmental destruction [43], which relates to the assumption by Giddens in the initial quotation. To analyze this, we can use Giddens' concept "rationalization of activities" of how people make sense of their activities [8]. Rationalization of activities concerns how people talk about and reflect on what they do. This connects what they do, and why they act. It is when asked to define what they know they could do in their households to counteract the environmental problems and in their explanations of why they do not perform these activities, that householders unveil constraints. All ideas for sustainable activities that are suggested in governmental policies that householders could perform, have to be incorporated in their everyday lives, and adjusted to all other goals and rationalities.

Households and families have often been placed on equal terms in sociological studies. A household's internal structures and workings both create and are recreated by larger-scale cultural, economic, and political processes [44]. The problematic aspects of defining "household" are the customary emphasis on negotiations, division of labor, and organization [45], which are difficult to apply to people living on their own. Here I argue that since so many people now live on their own, a household has to be liberated from a direct reference to families, at the same time as it has to be able to incorporate family functions and intergenerational negotiations. Parenting for example, tends to change household dynamics. As seen in the definition of sustainable development, hope is also placed in the "future generation", i.e., children and schooling. The concept ecological action space is not limited to a specific group of people, family size nor specific living conditions or isolated activities - but the everyday context. In that way we can notice how certain environmentally motivated activities are seen as viable or impossible to perform, how people are negotiating or prioritizing between them, etc.

To economize resources is one of the most central definitions of a household, and can be connected to the physical building/dwelling and the material and energy-related resources used in it, such as 
electricity, water, and fuel. When more and more people tend to live on their own [46], it implies increasing numbers of households and dwellings. This has been connected to increases in the use of material and energy consumption, through "a steadily rising number of goods and services provided by physical networks" [47], and socio-technological systems. The dwelling is a context in which people, depending on the type of housing arrangement (e.g., small house or apartment, subletting or ownership), can have an impact on and create conditions for acting in more (or less) environmentally friendly ways. The decision for how to live is a decision which in this sense has a form of a path dependence [41], since the householder will have different possibilities to influence the physical structures.

Information is often said to be a key to changing peoples' routines and lifestyles, but there is no linear correlation between increased information and knowledge, and changed practices [26,30,48,]. Information and knowledge are used, implemented, and changed in a household context, becoming part of how household members in cooperation "transfer ... facts into practice" [30]. In this transfer process, previous experience is just as important as available resources. The available information has to be considered relevant to behaviour and meaningful to the householders [26,30]. More knowledge may increase one's future options or choices.

The concept ecological action space is useful in investigations about how actors perceive their role in creating and solving environmental problems, and what actions they take in light of this. The concept is thus empirical rather than normative. Relevant questions for a study about ecological action space are: What activities are considered environmentally friendly? How do the actors conceive of their opportunities to act in environmentally friendly ways and what constraints are there? How do actors conceive of responsibilities for the environment, and how do they (attempt to) exert political influence? These questions are relevant not just for outspoken activists.

\subsection{Who Should Participate?}

There is a need to "politicize the private sphere", Dobson argues [4]. The private arena of household activities is as much a sphere for citizenship as the public arena, and thereby expands citizenship. The way feminists challenged the demarcation between private and public, in the 1960s and 1970s, has now been extended to other matters, such as sorting household waste and choice of mode of transportation. Through these connections, the household is included in the political sphere and is not considered solely a private domain. One of Dobson's main arguments is that citizens are already expected to "undertake responsibilities of citizenship in both the public and the private realms", and many public policies rely on responsible personal lifestyles [4]. Ecological citizenship is permeated by the ideal of individuals who do not act out of self-interest for monetary or material benefits, but out of virtue.

Ecological citizenship has received valid criticism on several counts. It places too much emphasis on individual responsibility and relies on extensive personal contributions, while neglecting the everyday preconditions of individual action [29,49,50]. One expectation as to what individuals and householders should do as ecological citizens concerns "the burdensome task of seeking, classifying, verifying, and updating" knowledge on what is ecologically sound or risky [51]. Another criticism is 
that the model relies too much on "optimistic voluntarism" [50]. By applying the concept of ecological action space, I will attempt to come to grips with this second criticism, by including constraints.

Societies are not "unified collectivities," When policies favoring sustainable development and ecology require that individuals take responsibility for the environment, it is important to investigate who precisely undertakes this responsibility, and who is accountable and affected [52]. Human actors are always embodied and embedded [52]. Women have generally been responsible for the household and the private sphere [25]. Knowledge and concern for the environment, as well as risk perception, can thus be gendered [52]. Barry goes as far as claiming that "being an environmental citizen is ... a part-time occupation" [49]. MacGregor [29] has made fundamental and valid criticism of the "male-centeredness" of ecological citizenship. Policies that are gender blind may simply mean more work for mothers [28], and rely on privatized and feminized caring. As MacGregor emphasizes, we have to look at the time needed to perform the green, unpaid household activities that are suggested, and how that will interact with the increased participation and time spent in the public domain in deliberative democratic activities [29]. Ecological citizenship is a normative ideal, which needs to be analysed empirically from a household perspective, taking account of the interactions and negotiations between members and others, and the everyday activities and how we recreate (un)sustainable practices through ordinary and routinized practices that are taken for granted [18].

\subsection{How to Participate?}

Since sustainable development has focused on participation in everyday activities, we should ask how to participate? Everyday life is composed of a myriad of activities, and in order to analyze the environmental effects the researcher has to focus on the details of specific activities, like how to wash clothes for example (what washing machine is used, what temperature, what detergent and softener, how are the clothes dried, who takes on the responsibility of washing, etc.). All the different possible choices for how to carry out the household activities make up an intricate and complex web that makes it difficult to measure who is more or less "sustainable" or environmentally friendly in the continuous weaving. Spaargaren argues that individuals do not choose what products to consume in isolation, but rather within "social arrangements" [32]. These "appears to have been composed of millions of individual decisions freely made by environmentally conscious households ...[but] individual choices would not have done them a bit of good if the town leaders had not decided on sustainable building programs ... [and] systems" [53]. This quotation emphasizes the "embeddedness of social action in socio-technical networks" [32], and is furthermore a good example of the interaction between individuals, and systems. Ecological action space pays attention to the situatedness of practice. Using structuration theory the concept highlights how actors rely on different systems in order to perform environmentally friendly activities, like recycling systems, eco-labels on food and products, public means of transportation, and so-called "green" energy that companies supply. This contributes with a more complex picture when discussing the individualization of responsibility for the environment. These systems reduce the complexity by facilitating choices, and may recreate structures. The ecological action space in this meaning has a place, a materiality, and depending on how the householders are situated, certain opportunities will seem viable. Structuration theory (in distinction from for example path dependence which could have been an option [41]) mainly focuses on structures 
in the sense of being social rules and culture. But structures have materiality which for the householders' ecological action space means that it relates to the walls and windows, energy systems, water taps, products and technical appliances, which nonetheless have immaterial aspects like comfort etc. It was this interaction that made structuration theory seems a viable as a base for the concept.

Citizens can get involved at different stages of the policy process, and may participate in decision-making regarding new paths towards sustainable development before a policy is determined or implemented [32], or in the legitimization and implementation of existing policies through their everyday activities and lifestyles. A central tenet in environmental studies of "participation" has been the connection to different forms of participation and the predilection for social protest, for example, in demonstrations [4], political consumption, buycotting, and boycotting [41], and civil disobedience and culture jamming [20], where the capitalist system is often at the center of the criticism, based on the analysis that it is the main cause of environmental destruction. These forms of activism have been considered as different from traditional parliamentary participation through voting and legislative change. Now participation has reached beyond traditional political arenas and reshaped both the actual political playing field and political theory [36].

When investigating the ideal of increased individual participation, the central concerns are citizens' self-perceived ability to participate and whether they believe that what they do matters, sometimes called "political efficacy". Putnam [54] refers to an ideal of collective mobilization that is distinct from individualized action, such as recycling waste or purchasing ecological products, not being considered collective action even if a great many people perform it.

The interchangeable use of the concepts householder, citizen, and consumer is central to understand sustainable development, and ecological action space in our contemporary society. The vision of "Small is Beautiful" is considered to create opportunities to act in the role of (non)consumer, since the central issue is whether we emphasize choosing the right products or the amounts of goods consumed, the latter alternative implying that a person may abstain from consuming. While some academic disciplines view consumer power as a form of political action, others consider it controversial to claim that consumption choices are examples of civic engagement $[1,55]$. Norén says that politically conscious consumer choices are "the little individual's opportunity to make her/his voice heard, and to feel solidarity, but without having to get engaged in formal organizations or spend time in lengthy meetings" [36] However, reducing citizenship to consumer action ignores the possibilities to work through government and traditional political processes [14,29].

... one of the great fallacies of the green consumer movement - that, after all, green or not, this

is a consumer movement, and the purpose of green companies is to promote more, not less, overall consumption [25].

Consumer studies have shown that there are culturally defined expectations of women: "women are apt to feel guilty; their compulsory feminine altruism is thereby exploited for the public (and increasingly corporate) good." [29] However, Micheletti states from a somewhat different point of view, that "women have historically been excluded from institutions of the public sphere ... Consumer choice was ... a site for women to participate in politics ... a site for their struggle for public recognition. Active political consumerism empowered women as citizens" [55]. Here political consumption is viewed as one of a range of ways in which the householder can act politically. 


\section{Conclusions}

In light of the politicization of everyday household activities, the abundant studies of sustainable development, and the individualized responsibility discourse in policies and green theories, this text has developed the what, who and how of the concept ecological action space. The framework is mainly built on structuration theory, but since sustainable development is a complex issue and studies are not lacking it has been related to several fields. Many previous studies of sustainable development build on a narrow view of the context in which individuals act, obviously for the pragmatic purpose of making the studied subjects researchable. By applying the analytical concept of ecological action space, I have argued that it is possible to capture the everyday aspects and householders' routines, with attention to what the environmental activities mean for them. Ecological action space has been related to individualization, household studies, ecological citizenship, and gendering. The ecological action space is the context in which individual actors and structures encounter and mutually create and recreate ideas about responsibility for the environment, and of what environmentally friendly activities that are performed. Ecological action space has a time dimension, in the sense that what is done here and now is based on previous experiences and actions, and simultaneously influences further activities. One's ecological action space communicates with other roles an individual may have, such as citizen, consumer, employee, householder, activist, and parent. There may be different rationales and motives for acting in the different roles, which the individual has to manage when living everyday life and choosing among alternatives for how to act.

The kind of empirical work that can be envisaged to develop the concept further would be a cross-national comparison of the construction of (individual) responsibility and ecological modernization at the household level in Sweden, with other cultural and political contexts where the individual responsibility may not be as accentuated.

Ecological action space can be useful to deepen the understanding of how risk perceptions, political participation, and distinctions between private (a sphere which should not be governed politically) and public are (re)created. While the majority of the structuring is done by routine, householders often know how to talk about and motivate some specific and symbolic environmental activities. Ecological action space is a relative concept in the sense that it focuses on the relationship between responsibility and opportunities and constraints to act environmentally friendly. Thereby it is distinct from ecological footprint for example, which measures how much of the earth's geographical area an average citizen uses; or ecological citizenship, which is normative and mainly focuses on what people ought to do. The ecological action space relates to what responsibilities people describe that they have for the environment, and how that is related to what opportunities and constraints the householders perceive as structuring their actions. Their ecological action space thus focuses on expectations, what resources and opportunities they can draw on, what they consider themselves to be in charge of in a specific situation (i.e., how they exert agency), and responsibility. Thereby it deals with how people actively structure their present and future opportunities to act environmentally friendly. The structuring is also what constrains their activities. Due to the attention given to both enabling and constraining factors in ecological action space, the concept has a dialectical dimension. It is fundamental where recycling stations are located and how many there are, how often the public means of transportation 
run, what energy systems that are supplied, where grocery stores are located, and how the parking lots are placed etc. yet, it is difficult to build a sustainable community into the physical structures.

\section{Acknowledgments}

This article has been elaborated with funds from The Swedish Research Council for Environment, Agricultural Sciences and Spatial Planning FORMAS, within the project "Radical Changes".

\section{Conflict of Interest}

The authors declare no conflict of interest.

\section{References and Notes}

1. Giddens, A. The Third Way: The Renewal of Social Democracy; Polity Press: Cambridge, UK, 1998.

2. Agenda 21 Förenta Nationernas Konferens om Miljö Och Utveckling; UNCED biblioteket; Nordstedts Tryckeri AB: Stockholm, Sweden, 1993.

3. Eliasoph, N. Avoiding Politics: How Americans Produce Apathy in Everyday Life; Cambridge University Press: Cambridge, UK, 1998.

4. Dobson, A. Citizenship and the Environment; Oxford University Press: Oxford, UK, 2003.

5. Segerberg, A. Thinking Doing: The Politicisation of Thoughtless Action; Elanders Gotab: Stockholm, Sweden, 2005.

6. Spaargaren, G.; Mol, A. Sociology, environment and modernity. Soc. Nat. Resour. 1992, 5, 323-344.

7. Langhelle, O. Why ecological modernization and sustainable development should not be conflated. J. Environ. Policy Plan. 2000, 2, 303-322.

8. Giddens, A. The Constitution of Society: Outline of the Theory of Structuration; Polity Press: Cornwall, UK, 1989.

9. Wackernagel, M.; Rees, W.E. Our Ecological Footprint: Reducing Human Impact on the Earth; New Society Publishers: Philadelphia, PA, USA, 1996.

10. Proposition 1990/91:90 En god livsmiljö, Swedish Government Bill; Sveriges Riksdag: Stockholm, Sweden, 1990-1991.

11. Fischer, F. Citizens, Experts and the Environment: The Politics of Local Knowledge; Duke University Press: Durham and London, UK, 2003.

12. Dryzek, J. Deliberative Democracy and Beyond: Liberals, Critics, Contestations; Oxford University Press: Oxford, UK, 2000.

13. Styrmedel; Swedish Environmental Protection Agency: Stockholm, Sweden, 2006. Available online: http://www.naturvardsverket.se (accessed on 10 June 2009).

14. Heath, J.; Potter, A. The Rebel Sell: How the Counterculture Became Consumer Culture; Capstone: Chichester, UK, 2006.

15. Sontag, S.; Bubolz, M. Families on Small Farms; Michigan State University: East Lansing, MI, USA, 1996. 
16. Schumacher, E.F. Small is Beautiful: A Study of Economics as if People Matter; Sphere: London, UK, 1974.

17. Att Handla Rätt Från Börja-En Kunskapsöversikt om hur Konsumtions- och Produktionsmönster kan bli mer Miljövänliga; von Borgstede, C., Duit, A., Hellsmark, H., Krantz Lindgren, P., Lövgren, K., Terrvik, E., Wickenberg, P., Eds.; Elanders Gotab: Stockholm, Sweden, 2002.

18. Shove, E. Comfort, Cleanliness and Convenience: The Social Organization of Normality; Berg: Oxford, UK, 2003.

19. Giddens, A. Modernity and Self-Identity: Self and Society in the Late Modern Age; Polity Press: Cornwall, UK, 1991.

20. Peretti, J.; Michelleti, M. The Nike sweatshop e-mail: Political consumerism, internet, and culture jamming. In Politics, Products and Markets: Exploring Political Consumerism Past and Present; Micheletti, M., Folles, A., Stolle, D., Eds.; Transaction Publishers: New Brunswick, NJ, USA, 2006.

21. Sewell, W. A theory of structure: Duality, agency, and transformation. Am. J. Soc. 1992, 98, 1-29.

22. De Certeau, M. The Practice of Everyday Life; University of California Press: Berkeley, CA, USA, 1984.

23. Highmore, B. Everyday Life and Cultural Theory; Routledge: London, UK, 2002.

24. Green, A. Hållbar Energianvändning i Svensk Stadsplanering: Från Visioner till Uppföljning $i$ Hammarby Sjöstad och Västra Hamnen; LiuPress: Linköping, Sweden, 2006

25. Seager, J. Earth Follies: Feminism, Politics and the Environment; Earthscan: London, UK, 1993.

26. Barr, S. Household Waste in Social Perspective: Values, Attitudes, Situations and Behaviour; Ashgate: Aldershot, UK, 2002.

27. Mårtensson, M.; Pettersson, R. Grön Vardag: Hushåll, Miljöhänsyn och Vardagspraktik; Brutus Östlings Bokförlag Symposion: Stockholm, Sweden, 2002.

28. Cowan, R.S. More Work for Mother: The Ironies of Household Technology from the Open Hearth to the Microwave; Basic Books: New York, NY, USA, 1983.

29. MacGregor, S. No sustainability without justice: A feminist critique of environmental citizenship. In Environmental Citizenship, Dobson, A., Bell, D., Eds.; The MIT Press: Cambridge, MA, USA, 2006.

30. Palojoki, P. The Complexity of Food Related Activities in a Household Context: A Study of Finnish Home Makers' Food Choices and Nutrition Knowledge; University of Helsinki: Helsinki, Finland, 1997.

31. Shiva, V. Staying Alive: Women, Ecology and Development; Zed: London, UK, 1989.

32. Spaargaren, G. Ecological modernization theory and the changing discourse on environment and modernity. In Environment and Global Modernity; Spaargaren, G., Mol, A., Buttel, F.H., Eds.; Sage: Thousand Oaks, CA, USA, 2000.

33. Hedrén, J. Naturen Som ett hot mot det moderna: Några ideologikritiska reflektioner. In Naturen som Brytpunkt_Om Miljöfrågans Mystifieringar, Konflikter och Motsägelser; Hedrén, J., Ed.; Symposion: Stockholm, Sweden, 2002. 
34. Aarhus Convention. Convention on Access to Information, Public Participation in Decision-making and Access to Justice in Environmental Matters; United Nations Economic Commission for Europe: Geneva, Switzerland, 1998. Available online: http://www.unece.org/ env/pp/mop2/Pictures/Gallery/ (accessed on 18 August 2008).

35. Brand, K.W. Environmental consciousness and behaviour: The greening of lifestyles. In The International Handbook of Environmental Sociology; Redclift, M., Woodgate, G., Eds.; Edward Elgar: Cheltenham; Northampton, UK, 1997.

36. Norén Bretzer, Y. Politiskt deltagande och styrning. In Hållbar Utveckling som Politik: Om Miljöproblemens Grundproblem; Jagers, S., Ed.; Liber: Malmö, Sweden, 2005.

37. Gupte, M.; Bartlett, R. Assessing the preconditions for deliberative democracy: Speaking truth to theory. Presented at The Annual Meeting of the Western Political Science Association, Marriott Hotel, Oakland, CA, USA, 17 March 2005.

38. Krantz Lindgren, P. Att färdas Som Man lär? Om Miljömedvetenhet och Bilåkande; Gidlund: Hedemora, Sweden, 2001.

39. Skill, K.; Gyberg, P. Framing devices in the creation of environmental responsibility: A qualitative study from Sweden. Sustainability 2010, 2, 1869-1886.

40. Oscarsson, H. Om individualisering. In Det Hyper-Individualiserade Samhället? Bjereld, U., Demker, M., Ekecrantz, J., Ekegren, A.M., Eds.; Boréa: Umeå, Sweden, 2005.

41. Hughes, T. The evolution of large technological systems. In The Social Construction of Technological Systems: New Directions in the Sociology and History of Technology; Bijker, W., Hughes, T., Pinch, T., Eds.; The MIT Press: Cambridge, MA, USA, 1987.

42. Giddens, A. Living in a post-traditional society. In Reflexive Modernization: Politics, Tradition and Aesthetics in the Modern Social Order; Beck, U., Giddens, A., Lash, S., Eds.; Polity Press: Cambridge, UK, 1994.

43. Beck, U. Att Uppfinna det Politiska: Bidrag till en Teori om Reflexiv Modernisering; Daidalos: Uddevalla, Sweden, 1996.

44. Moore, H. A Passion for Difference: Essays in Anthropology and Gender; Polity Press: Cambridge, UK, 1994.

45. The Household Economy: Reconsidering the Domestic Mode of Production; Wilk, R., Ed.; Westview Press: Boulder, CO, USA, 1989.

46. Bladh, M. Hushållens elförbrukning: Utvecklingen totalt och i Detalj 1980-2000; Working Paper 291; Tema Technology and Social Change, Linköping University: Linköping, Sweden, 2005.

47. Green Households? Domestic Consumers, Environment and Sustainability; Noorman, K.J., Schoot Uiterkamp, T., Eds.; Earthscan: London, UK, 1998.

48. Shanahan, H.; Carlsson-Kanyama, A.; Pipping Ekström, M. Exploring opportunities for eco-sound food habits. Households and research in partnership. Kappa Omicron FORUM 2002, $14,1-15$.

49. Barry, J.; Resistance is fertile: From environmental to sustainability citizenship. In Environmental Citizenship; Dobson, A., Bell, D., Eds.; The MIT Press: Cambridge, MA, USA, 2006.

50. Hayward, T. Ecological citizenship: Justice, rights and the virtue of resourcefulness. Environ. Polit. 2006, 15, 435-446. 
51. Luque, E. Researching environmental citizenship and its publics. Environ. Polit. 2005, 14, 211-225.

52. Mellor, M. Feminism and Ecology; Oxford Polity: New York, NY, USA, 1997.

53. Spaargaren, G.; van Vliet, B. Lifestyles, consumption and the environment: The ecological modernisation of domestic consumption. Environ. Polit. 2000, 9, 50-77.

54. Putnam, R. Bowling Alone: The Collapse and Revival of American Community; Simon \& Schuster: New York, NY, USA, 2000.

55. Micheletti, M. Political Virtue and Shopping-Individuals, Consumerism and Collective Action; Palgrave Macmillan: New York, NY, USA, 2003.

(C) 2012 by the authors; licensee MDPI, Basel, Switzerland. This article is an open access article distributed under the terms and conditions of the Creative Commons Attribution license (http://creativecommons.org/licenses/by/3.0/). 